RESEARCH ARTICLE

\title{
Anthelmintic Potency of Carica papaya seeds against Gastro-intestinal Helminths in Red Sokoto goat
}

\author{
S. A. Ameen 1," , O.M. Azeez ${ }^{3}$, Y. A. Baba ${ }^{1}$, L. O. Raji², A. Basiru ${ }^{3}$, K. T. Biobaku ${ }^{4}$, G. J. Akorede ${ }^{4}$ A. O. Ahmed ${ }^{5}$, A. \\ O. Olatunde ${ }^{2}$ and I. A. Odetokun ${ }^{6}$
}

${ }^{1}$ Department of Veterinary Medicine, University of Ilorin, Ilorin, Nigeria

${ }^{2}$ Department of Veterinary Theriogeneology and Production, University of Ilorin, Ilorin, Nigeria

${ }^{3}$ Department of Veterinary Physiology and Biochemistry, University of Ilorin, Ilorin, Nigeria

${ }^{4}$ Department of Veterinary Pharmacology and Toxicology, University of Ilorin, Ilorin, Nigeria

${ }^{5}$ Department of Veterinary Microbiology, University of Ilorin, Ilorin, Nigeria

${ }^{6}$ Department of Veterinary Public Health and Preventive Medicine, University of Ilorin, Ilorin, Nigeria

Received:14/9/2017; Accepted:03/04/2018

\begin{abstract}
The comparative studies on anthelmintic potency of Carica papaya seeds was investigated in naturally infected Red Sokoto goats. Forty Red Sokoto goats (average $12 \pm 0.25 \mathrm{~kg}$ body weight) infected naturally with helminthes were used to compare anthelminthic potency of Carica papaya seeds in aqueous and crude extract forms and Thiabendazole treatment against intestinal worms. The animals were randomly assigned into four treatment groups (A, B, C and D) consisting of 10 Red Sokoto goats per group. The animals in group A were not treated (negative control) while B undergone thiabendazole anthelmintic treatment (positive control). Groups $\mathrm{C}$ and $\mathrm{D}$ were given the powdery and aqueous forms of C. papaya seed extract via feed at $300 \mathrm{mg} /$ $\mathrm{kg}$ body weight/day and at $1: 10 \mathrm{ml}(\mathrm{w} / \mathrm{v})$ of water respectively for 3 days. Before anthelmintic treatments and $1^{\text {st }}$ and $2^{\text {nd }}$ weeks after administering the anthelminthics, faecal and blood samples were collected for parasitological and haematological analysis. Data collected were subjected to one-way ANOVA. Treatments of both aqueous and powdery forms of $C$. papaya seed extract resulted a significant increase $(\mathrm{p}<0.05)$ in packed cell volume (PCV), red blood cell (RBC) and haemoglobin concentration and lymphocyte counts. Conversely, there was significant $(p>0.05)$ decrease in the eosinophil counts. The reduction in the faecal egg counts of helminth when $C$. papaya seed extracts applied was significantly $(p<0.05)$ comparable to those obtained for Thiabendazole treatment. However, the efficacy of aqueous form of $C$. papaya seed extract was more significant $(p<0.05)$ than the crude (powdery) extract administered via the feed. The study therefore concludes that C. papaya seed extracts have comparable anthelmintic potency to Thiabendazole and that aqueous forms were more efficient than powdery forms when administered in Red Sokoto goats as an alternative to anthelmintic to synthetic dewormers in rural areas in controlling helminthosis.
\end{abstract}

Keywords: Carica papaya seeds, Red Sokoto goats, Helminths, Anthelmintics, Thiabendazole.

\section{INTRODUCTION}

Goats are small ruminants which play a significant role in the food chain and overall livelihoods of rural households especially in developing countries (Lebbie, 2004; Alhaji and Odetokun, 2013). These animals can be reared for various reasons such as income generation, religious purposes, household consumption and as a security against crop failure (Maikasuwa and Jabo 2014). Goat contributes between $16-24 \%$ of domestically produced meat in Nigeria (Okewu and Iheanacho, 2015). Despite the huge potential in small ruminant farming, there are challenges of diseases, parasites and lack of adequate nutrition (Chah et al., 2013). Gastro intestinal parasites are one of the most neglected areas of veterinary care in Africa (Adedeji et al., 2013). This is partly due to the fact that the clinical signs of the infection are less obvious than other disease conditions. For instance, severe helminthoses such as Haemochus contortus infection causes anemia in goats (Ameen et al., 2006), and if not treated, leading to death of infected animals. There are conventional anthelmintic drugs against gastrointestinal parasites of small ruminants, the efficacies of conventional medicaments against parasitic diseases have been reported with variable success (Basu and Haldar, 1994). However, the toxic effects of these chemicals on humans (Murray et al., 1992), development of resistance to it by target parasites (Maingi et al., 1996) as well as high cost of drugs (Chema et al., 1990) paved way for herbal remedies as reasonable alternatives.

Fajimi and Taiwo, (2004) reported that herbal therapies are natural products thus making them environmentally friendly and cheap. Carica papaya (Linn), commonly known as papaya is a fruit crop cultivated in tropical and subtropical regions, and well known for its nutritional benefits and medicinal applications (Ming et al., 2008). The antimicrobial, antifungal, larvicidal (Wabo et al., 2011) and antiprotozoal properties of $C$. papaya against

*Corresponding Author's Email: ameen.sa@unilorin.edu.ng 
Trichomona vaginalis have been reported (Calzada et al., 2007). The seeds of Carica papaya have been evaluated as an anthelmintic therapy against gastro intestinal nematode worms in human (Okeniyi et al., 2007) but has not been fully substantiated in Red Sokoto goats (Okeniyi et al., 2007; Ameen et al., 2010). This work therefore compared anthelmintic efficacy of $C$. papaya seeds in powdery and aqueous forms against standard proprietary anthelminthics (Thiabendazole) in Red Sokoto goat naturally infected with gastro-intestinal worms.

\section{MATERIALS AND METHODS}

\section{Collection and preparation of the $C$. papaya seeds}

The seeds were collected freshly from ripe pawpaw fruits and washed with clean water to remove dirt and other contaminants like bacteria. The seeds were sun-dried and grinded into a powdery form. The pawpaw seed powder of $75 \mathrm{~g}$ was blended into liquefaction in $150 \mathrm{~mL}$ of distilled water. The mixture was then centrifuged at 1,500 rpm. The supernatant was filtered through sterile filter paper into a conical flask as the study extract. A $1 \mathrm{ml}$ of filtrate is expected to contain $0.5 \mathrm{~g}(500 \mathrm{mg} / \mathrm{ml})$ of the active ingredients of the carica seed powder.

\section{Proprietary Anthelmintic (Thiabendazole)}

The daily dose of Thiabendazole for the therapeutic use in the Nigerian goats is $50 \mathrm{mg} / \mathrm{kg}$ body weight in divided doses for 3 consecutive days. For an example, an animal weighing $10 \mathrm{~kg}$ will receive $500 \mathrm{mg}$ of active ingredient per day (Hansen and Perry, 1990). This is amounted to 5 tablets per day since each tablet of Thiabendazole contains $100 \mathrm{mg}$ of active ingredients.

\section{Experimental animals}

Forty Red Sokoto goats used in this study were procured from the local market in Ogbomoso, Oyo State, Nigeria. They were kept in concrete-floored, cleaned and separate pens in the Ladoke Akintola University of Technology Teaching and Research Farm, Faculty of Agriculture, Ogbomoso, Nigeria. All the animals were fed and given water ad-libitum. The pen was fumigated before the animals were moved in. They were acclimated to their new environment for two weeks before the commencement of the experiment. All experimental protocols were in compliance with Ladoke Akintola University of Technology Ethics Committee on Research in Animals as well as internationally accepted principles for animal use and care.

\section{Animal grouping and treatment}

Forty Red Sokoto goats (average $12 \pm 0.25 \mathrm{~kg}$ bodyweight; 12 months of age as observed using dentition method with no history of prior deworming were used in the experiment. The Red Sokoto goats were divided into four groups (A, B, $\mathrm{C}$ and $\mathrm{D}$ ) with 10 animals per group. The animal in group A received no medication (control); $\mathrm{B}$ were treated with Thiabendazole, the group $\mathrm{C}$ had the extract administered at $300 \mathrm{mg}$ per day as feed additives (Hansen and Perry, 1990), while D was drenched with the aqueous crude extract of
C. papaya at $1: 10 \mathrm{ml}(\mathrm{w} / \mathrm{v})$ of water. Both the drug and the extracts were administered for 3 consecutive days. This procedure was repeated after 2 weeks.

\section{Haematological and parasitological analysis}

Faecal sample of each goat was collected in labelled sterile universal bottles for identification of the type of helminths eggs present using flotation techniques. Blood samples were also collected from each animal into labelled EDTA bottles for haematology. After 2 weeks of initial stabilization, the pretreatment haematological and coprological evaluations were made. The flotation method, (Hansen and Perry,1990) which involved the use of salt $(\mathrm{NaCl})$ water, was used to determine the presence of helminth eggs in the faecal samples, while the modified McMaster egg-counting technique was used for nematode counts. Blood samples were collected from the jugular vein of each goat using $5 \mathrm{ml}$ syringes and 25-gauge needles into appropriately labelled EDTA bottles. Estimation of haemoglobin $(\mathrm{Hb})$ concentration was by Sahli's method. Erythrocytes and leucocytes were counted manually using Neubau's haemocytometer (Jain,1986). Packed cell volume (PCV) was determined conventional microhaematocrit method in which leucocyte differential counts were also determined (Mitruka and Rawsley, 1977; Jain, 1986).

\section{Statistical analysis}

The data obtained from the coprological and haematological evaluation were expressed as the mean of parameters \pm standard error (SE). Differences between means were evaluated using the Analysis of Variance (ANOVA) using completely randomized design by SAS package (2004) and the significance of the treatment values was separated by Duncan multiple range test at $(\mathrm{p}<0.05)$ (Field, 2009).

\section{RESULTS}

\section{Faecal Egg Counts}

Initially, that all the Red Sokoto goats were heavily contaminated with worms ranging from Haemochus contortus, Oesophagostomum sp., Trichostrogylus sp. and Cooperia sp.. All the worms were cleared after the first dose in groups B and D, and following the second treatment in group $\mathrm{C}$. There was a significant reduction $(\mathrm{p}<0.05)$ in egg counts in group $\mathrm{C}$ and $\mathrm{D}$ compared with the negative control (Group A) (Table 1).

\section{Haematology}

Haematological report showed that before treatment, the PCV mean values for animals in groups A, B,C and D were $19.00 \pm 0.6,24.50 \pm 0.8,20.0 \pm 0.6$ and $24.00 \pm 1.2$ respectively. After treatments, these parameters showed a significant increase. The haemoglobin values before treatment in groups A, B, C and D were $6.6 \pm 0.2,8.3 \pm$ $0.4,7.4 \pm 0.3$ and $7.5 \pm 0.4$ respectively. After treatments, this parameter too showed a significant increase. In the case of the red blood cell (RBC), the mean values for groups $\mathrm{A}, \mathrm{B}, \mathrm{C}$ and $\mathrm{D}$ before treatment were $6.7 \pm 0.1,8.2 \pm 0.5$, $7.2 \pm 0.3$ and $7.8 \pm 0.3$ respectively. The $\mathrm{RBC}$ also showed a significant increase following the treatments in tandem 
Table 1: Helminths' faecal egg counts in naturally infected Red Sokoto Goats treated with the drug, Carica papaya seed powder and aqueous extract.

\begin{tabular}{|c|c|c|c|c|}
\hline & \multirow[b]{2}{*}{ Groups } & \multicolumn{3}{|c|}{ Faecal egg counts (mean $\pm \mathrm{SE})($ per gram of faeces) } \\
\hline & & Pretreatment & ${ }^{\#} 1^{\text {st }}$ Application & ${ }^{\text {\#\# } 2^{\text {nd }} \text { Application }}$ \\
\hline \multirow[t]{4}{*}{ Haemonchus contortus } & A & $2400 \pm 1.2$ & $2500 \pm 0.6$ & $2600 \pm 0.2$ \\
\hline & $\mathrm{B}$ & $2300 \pm 0.6$ & 0.00 & 0.00 \\
\hline & $\mathrm{C}$ & $2200 \pm 1.7$ & $* 700 \pm 0.4$ & 0.00 \\
\hline & $\mathrm{D}$ & $2300 \pm 1.2$ & 0.00 & 0.00 \\
\hline \multirow[t]{4}{*}{ Oesophagostomum spp } & A & $400 \pm 0.4$ & $600 \pm 2.6$ & $600 \pm 0.4$ \\
\hline & $\mathrm{B}$ & $500 \pm 0.6$ & 0.00 & 0.00 \\
\hline & $\mathrm{C}$ & $600 \pm 0.5$ & $* 100 \pm 0.1$ & 0.00 \\
\hline & $\mathrm{D}$ & $400 \pm 0.2$ & 0.00 & 0.00 \\
\hline \multirow{4}{*}{ Cooperia spp } & A & $1200 \pm 0.4$ & $1000 \pm 0.1$ & $1200 \pm 0.2$ \\
\hline & $\mathrm{B}$ & $1000 \pm 0.4$ & 0.00 & 0.00 \\
\hline & $\mathrm{C}$ & $1200 \pm 0.6$ & $* 700 \pm 0.4$ & 0.00 \\
\hline & $\mathrm{D}$ & $1200 \pm 0.5$ & 0.00 & 0.00 \\
\hline \multirow[t]{4}{*}{ Trichostogylus spp } & A & $800 \pm 0.4$ & $1200 \pm 0.3$ & $1200 \pm 0.4$ \\
\hline & B & $600 \pm 0.2$ & 0.00 & 0.00 \\
\hline & $\mathrm{C}$ & $800 \pm 0.5$ & $* 700 \pm 0.4$ & 0.00 \\
\hline & $\mathrm{D}$ & $700 \pm 0.4$ & 0.00 & 0.00 \\
\hline
\end{tabular}

\#2 weeks after the $1^{\text {st }}$ application of drug/C. papaya in powder and aqueous extracts;

* indicates significant difference $(\mathrm{P}<0.05)$ between animals in $\mathrm{A}, \mathrm{B}, \mathrm{C}$ and $\mathrm{D}$ after 1 st application of drugs/C.papaya in powdery and aqueous extracts.

\#2 weeks after the $2^{\text {nd }}$ application of drug/C. papaya in powder and aqueous extracts.

Table 2: Haemograms of Red Sokoto Goats naturally infected with helminthes and treated with Drug/Carica papaya seed in powder and aqueous form

\begin{tabular}{|c|c|c|c|c|}
\hline Blood Parameters & Groups & Pretreatment & ${ }^{\#} 1^{\text {st }}$ Treatment & $2^{\text {nd }}$ Treatment \\
\hline \multirow[t]{4}{*}{ PVC (\%) } & A & $20.00 \pm 0.4$ & $19.00 \pm 0.2$ & $18.00 \pm 0.4$ \\
\hline & B & $22.00 \pm 0.6$ & $28.00 \pm 0.5$ & $30.00 \pm 0.5$ \\
\hline & $\mathrm{C}$ & $20.00 \pm 0.6$ & $25.00 \pm 0.4$ & $29.00 \pm 0.3$ \\
\hline & $\mathrm{D}$ & $21.00 \pm 0.4$ & $28.50 \pm 0.6$ & $32.00 \pm 1.2$ \\
\hline \multirow[t]{4}{*}{$\mathrm{Hb}(\mathrm{g} / \mathrm{dL})$} & A & $7.2 \pm 0.5$ & $7.1 \pm 0.7$ & $7.2 \pm 0.2$ \\
\hline & $\mathrm{B}$ & $7.2 \pm 0.3$ & $9.2 \pm 0.2$ & $10.4 \pm 1.2$ \\
\hline & $\mathrm{C}$ & $7.1 \pm 0.6$ & $9.1 \cdot, 1 \pm$ & $9.5 \pm 0.1$ \\
\hline & $\mathrm{D}$ & $7.2 \pm 0.1$ & $9.4 \pm 0.5$ & $9.8 \pm 0.6$ \\
\hline \multirow[t]{4}{*}{$\mathrm{Rbc} \times\left(10^{6} / \mathrm{mm}^{3}\right)$} & A & $8.2 \pm 0.4$ & $8.0 \pm 0.6$ & $7.8 \pm 0.4$ \\
\hline & B & $8.1 \pm 0.6$ & $9.6 \pm 0.4$ & $10.2 \pm 0.5$ \\
\hline & $\mathrm{C}$ & $8.0 \pm 0.4$ & $9.7 \pm 1.2$ & $10.4 \pm 1.3$ \\
\hline & $\mathrm{D}$ & $8.2 \pm 0.4$ & $9.7 \pm 1.2$ & $10.4 \pm 1.3$ \\
\hline \multirow[t]{4}{*}{ Lymphocytes (\%) } & A & $50 \pm 0.5$ & $45 \pm 0.6$ & $40 \pm 0.5$ \\
\hline & $\mathrm{B}$ & $50 \pm 0.2$ & $55 \pm 0.5$ & $56 \pm 1.2$ \\
\hline & $\mathrm{C}$ & $52 \pm 1.2$ & $54 \pm 0.2$ & $56 \pm 0.5$ \\
\hline & $\mathrm{D}$ & $52 \pm 1.4$ & $56 \pm 0.2$ & $58 \pm 0.4$ \\
\hline \multirow[t]{4}{*}{ Eosinophil (\%) } & A & $2.1 \pm 0.2$ & $2.2 \pm 0.2$ & $2.3 \pm 0.2$ \\
\hline & B & $2.1 \pm 0.4$ & 0.00 & 0.00 \\
\hline & $\mathrm{C}$ & $2.2 \pm 0.6$ & $1.2 \pm 0.4$ & 0.00 \\
\hline & $\mathrm{D}$ & $2.3 \pm 1.2$ & 0.00 & 0.00 \\
\hline
\end{tabular}

\#2 weeks after the $1^{\text {st }}$ application of drug/C. papaya in powder and aqueous extracts;

\#2 weeks after the $2^{\text {nd }}$ application of drug/C. papaya in powder and aqueous extracts. 
with first two parameters. Moreover, lymphocyte mean values likewise showed increasing levels while eosinophil values decreased following the treatments (Table 2).

\section{DICUSSION}

The powder and aqueous extracts of $C$. papaya administered in this study caused a significant reduction in the worm infection among the goats. The goats in group D particularly experienced more significant reduction in worm infection than goats in group $\mathrm{C}$ following the second application. This observation may probably be due to the fact that animals may not pick enough and sufficient active ingredients being fed during the first week of application in additive forms unlike oral doses that were drenched directly into the gastrointestinal tract where helminthes in the intestinal tract had direct contact with the extract. This is corroborated by the findings of Okeniyi et al., (2007) who reported $71-100 \%$ worm clearance in asymptomatic children administered with $C$. papaya seeds and honey. Carica papaya seeds contain many biologically active compounds mainly parpain and benzylisothiocyanate (Nwofia et al., 2012). Moreover,the seeds have high crude protein, good source of minerals such as magnesium, phosphorus and calcium. The presence of some antinutritional factors such as taninis, trypsin inhibitors, phytic and oxalate were also noted (Elezuo et al.,2012). The effects of the powdery and aqueous extracts of $C$. papaya seeds were not pronounced on the worms than those of proprietary anthelimintics in the present study perhaps may attributed to the low bioavailability of active compounds that normally characterized medicinal plants (Deepthi et al., 2013). Administration of the drug and extracts resulted in a remarkable improvement in the haematological parameters of animals in Groups B, C and D. In addition to the reduction in worm burden, $C$. papaya seeds have also been reported to contain minerals and vitamins which are essential for haemopoiesis (Nwofia et al., 2012). The total reliance on imported proprietary drugs can be reduced by introducing herbal remedies such as powder and aqueous extracts of $C$. papaya. Introducing herbal remedies also could reduce the risk of drug resistance to some extent.

\section{CONCLUSION}

The study proved that the seeds of Carica papaya has comparable anthelmintic effect to proprietary anthelmintics (Thiabendazole) in Red Sokoto goat. However, further research is needed to isolate the active ingredient responsible for the anthelmintic effect and to improve its bioavailability.

\section{REFERENCES}

Adedeji, O.S., Akande, T.O., Akinwumi, A.O., Okunlola, D.O. and Shittu, M.D. (2013). Ethnoveterinary practices among sheep rearers in Ona-Ara Local Government of Oyo State, Nigeria. Sokoto Journal of Veterinary Science. 11(1): 38-44.

Alhaji, N.B. and Odetokun, I.A. (2013). Food security and economic implication of small ruminant fetal wastages in Nigeria: a case of an abattoir. Livestock
Research for Rural Development. Volume 25(5): Article \#79. Retrieved August 25, 2016, from http://www.lrrd. org/lrrd25/5/alha25079.htm.

Ameen, S.A., Joshua R.A., Adedeji, O.S., Ige, O.A., Oyebanji, B.O., Ogundola, A.F., and Rafiu, T.A. (2006). Experimental Studies on Gastro-intestinal Nematode Infection; clinical observation and haematological changes following Haemonchus contortus Infection in kid goats. Journal of Animal and Veterinary Advances 5: 511-514.

Ameen, S.A., Adedeji, O.S., Ojedapo, L.O., Salihu, T. and Fabusuyi, C.O. (2010). Anthelmintic Potency of Pawpaw (Carica papaya) Seeds in West African Dwarf (WAD) Sheep. Global Veterinaria 5 (1): 30-34.

Basu, A.K., and Aaldar, D.P. (1994). An in-vitro study of the efficacy of Sevin (Inapthyl-methyl-carbamate) on ectoparasites of livestock. Bulletin of Animal Health and Production Africa, 42: 303-305.

Bradford, H. A. and Hill, I. H. (1991). Principles of Medical Statistics, 12 ${ }^{\text {th }}$ Edition; Edward Arnold, London. Pp. 9.

Calzada, F., Yépez-Mulia, L. and Tapia-Contreras, A. (2007). Effect of Mexican medicinal plant used to treat trichomoniasis on Trichomona vaginalis trophozoites. Journal of Ethnopharmacology 113: 248-251.

Chah, J.M., Obi, U.P., and Ndofor-Foleng, H.M. (2013). Management practices and perceived training needs of small ruminant farmers in Anambra State, Nigeria. African Journal of Agricultural Research 8 (22): 27132721.

Chema, S. and Ward, D. 1990. Cost effective disease control routines and animal health management in animal agriculture. Proc.FAO Expert Consultation held in Rome, Italy between 10-14 December, 1990.

Deepthi, V.T., Varsha, B.B., Priya, J.K., Varsha, M.J. and Vilasrao, K. (2013). Natural Bioenhancers: An overview. Journal of Pharmacognosy and Phytochemistry 2(3): 55-60.

Elezuo, K.O., Akalonu, N.M., and Eboigbe, J.J. (2012). Evaluation of the nutrient composition of some unconventional feedstuffs. Continental Journal of Fisheries and Aquatic Science, 5(2): 1-5.

Fajimi, A.K., Taiwo, A.A., Ayodeji, I.O., Adebowale, E.A. and Ogundola, F.I. (2001). Therapeutic trials on gastrointestinal helminth parasite of goats using pawpaw seeds as a drench. Proceedings of the international conference on sustainable crop. Livestock prod. for improved livelihoods and nat. res. Managt. West Afr. held at the International Livestock Research Institute (ILRI) in partnership with International Institute of Tropical Agriculture between Nov. 9-23, 2001.

Field, A. (2009). Discovery of Statistics using SPSS for window standard version, SAGE.

Hansen, J. and Brian, P. (1990). A Handbook on the Epidemiology, Diagnosis and Control of Gastrointestinal Parasites of Ruminants in Africa, Pp: 55-61.

Jain, N.C. (1986). Schalm's Veterinary Haematology, 4 ed. Lea and Febiger, Philadelphia, U.S.A USA, Inc. 42-58 Pp.

Lebbie, S.H.B. (2004). Goats under Household Conditions. Small Ruminant Research 51: 131-136. 
Maikasawa, M.A. and Jabo, M.S.M. (2014). Analysis of sheep and goats marketing in Sokoto metropolis, Sokoto state, Nigeria. International Journal of Agricultural Science and Veterinary Medicine 2(1): 1-4.

Maingi, N.H., Bjorn, S.M., Tharmsborg, H.O., Bogh, P., and Nansen (1996). A survey of anthelmintic resistance in nematode parasites of goats in Denmark. Veterinary Parasitology, 66: 53-66.

Ming, R., Hou, S., Feng, Y., Yu, Q., Dionne-Laporte, A., Saw, J.H., Senin, P., Wang, W., Ly, B.V. and Lewis, K.L. (2008). The draft genome of the transgenic tropical fruit tree papaya (Carica papaya Linnaeus). Nature 452: 991-996.

Mitruka, B.M. and Rawnsley, H.M. (1977). Clinical Biochemical and Haematological Reference Values in normal experimental animals, Masson Publishing.

Murray, V.S., Wiseman, H.H., Dawlings, S., Morgan, I., Houseman, I.M. (1992). Health effects of organophosphate sheep dips. British Veterinary Journal, 305: 1090.

Nwofia, G.E, Ojimelukwe, P. and Eji, C. (2012). Chemical composition of leaves, fruit pulp and seeds in some Carica papaya (L) morphotypes. International Journal of Medical and Aromatic Plant, 2(1): 200-206.
Okewu, J. and Iheanacho, A.C. (2015). Profitability of Goat Marketing in Benue State, Nigeria: A Study of Selected Local Government Areas. International Academic Journal of Educational Research, 10(2): 54-74.

Okeniyi, J.A., Ogunlesi, T.A., Oyelami, O.A. and Adeyemi, L.A. (2007). Effectiveness of dried Carica papaya seeds against human intestinal parasitosis: A pilot study. Journal of Medicine and Food. 10, 194-196.

S.A.S.(2004).User's guide Statistical analysis, What is new in SAS/STAT 9 and 9.1.Pp: 57-68

Soulby, E.J.L, (1982). Helminths, Arthropods and Protozoa of Domestic Animals. (7th ed.). Balliere, Tindall, London.

Wabo, P.J., Ngankam, N.J.D., Bilong, C.F. and Mbida, M.A (2011). Comparative study of the ovicidal and larvicidal activities of aqueous and ethanolic extracts of pawpaw seeds Carica papaya (Caricaceae) on Heligmosomoides bakeri. Asian Pacific Journal of Tropical Medicine 4, 447-450. 